\section{RANCANG BANGUN PEREKAYASAAN PABRIK ACUAN SEPATU PRIA DARI BAHAN HDPE}

\author{
Oleh : Arum Yuniari, Niken Karsiati, Irene Sri Sukaeni
}

\begin{abstract}
The aim of this research is to find out process of production and the relation between cost, sell price and percentage of break even point. Production of capacity planned is 480 pairs per day, so that in a year with 288 work day the capacity produced is 138,240 pairs of man shoe lasting. Manufacturer works for 8 hours a day. The economical calculations are as follows : the total capital is fixed capital + working capital $=R p 2,257,640,603.00$, the total production cost is variable cost a year + fixed cost a year $=R p 2,031,829,715.00$; the manufacturing cost $=R p$ $14,698.00$ /pairs, the profit calculation before taxing is Rp 627,631,405.00, after taxing is Rp 502,105,124.00; the pay out period calculation consists of the percentage of profit to return the capital (rate of return) before taxing is $27.80 \%$, after taxing is $22.24 \%$ and the pay out period before taxing 2 year 11 months, after taxing 3 year 6 months the break even calculation consists of the break even point is $\mathrm{Rp} 1,387,146,821.00$, the percentage of break even point is $53.82 \%$ and the capacity of break even point is 7,440,077 pairs shoe last.
\end{abstract}

\section{INTISARI}

Penelitian ini bertujuan untuk mengetahui proses produksi dan hubungan antara biaya, harga jual dan prosentase batas rugi laba. Kapasitas produksi direncanakan sebesar 480 pasang per hari, sehingga dalam 1 tahun dengan 288 hari kerja kapasitas yang dihasilkan 138.240 pasang acuan sepatu pria. Satu hari pabrik bekerja selama 8 jam. Dari perhitungan analisa ekonomi diperoleh hasil sebagai berikut : Total modal yang terdiri dari modal tetap dan modal kerja $=\mathrm{Rp}$ 2.257.640.603,00 ; biaya produksi yang terdiri dari biaya tidak tetap 1 tahun dan biaya tetap 1 tahun $=R p 2.031 .829 .715,00$. Harga pokok produksi $=R p 14.698,00 /$ pasang. Keuntungan sebelum pajak Rp 627.631.405,00; sesudah pajak Rp $502 \cdot 105 \cdot 124,00$. Keuntungan pengembalian modal sebelum pajak $=27,80 \%$, sesudah pajak $=22,24 \%$ dan waktu pengembalian modal sebelum pajak $=2$ tahun 11 bulan, sesudah pajak 3 tahun 6 bulan. Perhitungan nilai batas rugi laba $=\mathrm{Rp}$ 1.387.146.821,00 dan prosentase batas rugi laba $=53.82 \%$ serta kapasitas batas rugi laba $=7.440 .077$ pasang acuan sepatu.

\section{PENDAHULUAN}

Acuan sepatu merupakan sarana penting dalam proses pembuatan sepatu dan alas kaki lainnya, karena memegang peranan dalam menentukan bentuk dan model sepatu yang dikehendaki serta menentukan kenyamanan pakai.

Acuan sepatu dapat dibuat dari kayu, plastik dan alumunium. Pada umumnya pabrik sepatu dengan sistem vulkanisasi dan injeksi menggunakan acuan dari aluminium yang harganya relatif mahal. Sedangkan pada pembuatan sepatu dengan sistem lem digunakan acuan dari kayu, akan tetapi acuan dari kayu ini tidak tahan lama dan hanya jenis kayu tertentu saja yang dapat digunakan.

Acuan sepatu yang terbuat dari bahan plastik akan lebih menguntungkan dibandingkan dengan acuan yang terbuat dari kayu dan aluminium, diantaranya adalah tahan terhadap perubahan cuaca, penyediaan bahannya mudah, tahan terhadap pukulan, dapat dirubah bentuknya, pembuatannya mudah dan harganya lebih murah dari pada acuan sepatu dari aluminium. Jenis plastik yang digunakan adalah polietilena, khususnya High Density Polyethylene.

\section{TINJAUAN PUSTAKA}

Acuan sepatu merupakan suatu sarana yang digunakan sebagai cetakan dalam proses pembuatan sepatu, sehingga untuk membuat acuan tersebut diperlukan aturan-aturan dan ukuran yang sesuai dengan bentuk dan ukuran kaki. Selain itu acuan sepatu dapat berfungsi sebagai salah satu alat untuk menambah keserasian pakai dengan memberikan rasa enak dan nyaman. Bahan yang dapat digunakan untuk membuat acuan sepatu antara lain kayu, aluminium dan plastik.

Bahan plastik mempunyai sifat yang unik, di antaranya mudah dibentuk, tahan terhadap bahan kimia, mudah disesuaikan dengan beberapa teknik pembuatan dan sangat ekonomis. Dalam pembuatan acuan sepatu, bahan baku plastik yang digunakan adalah bahan polietilen. Ditinjau dari sifat fisiknya, PE mempunyai sifat antara lain mudah diproses, fleksible dan liat, sifat dielektriknya baik, tahan terhadap zat kimia kecuali asam oksidator, sifat permeabilitasnya terhadap uap air kecil, tidak berbau dan tidak beracun. Ada bebrapa keuntungan dari acuan sepatu 
dari bahan plastik ini, antara lain : tahan terhadap perubahan cuaca, pembuatannya lebih mudah daripada acuan dari bahan aluminium, harga relatif murah, tahan terhadap pukulan dan mudah dibentuk.

\section{MATERI DAN METODE PENELITIAN}

Materi

Materi yang digunakan dalam penelitian ini adalah data sekunder yang diperoleh dari hasil penelitian yang dilakukan di BBKKP dan studi pustaka yang berkaitan dengan rancang bangun pabrik acuan sepatu plastik HDPE. Kapasitas produksi direncanakan sebesar 480 pasang per hari atau 138.240 pasang per tahun.

\section{Metode Penelitian}

Data yang diperoleh dari hasil penelitian diolah dengan menggunakan metode menurut Peter dan Thimmerhaus, 1978, sehingga dapat diketahui :

Prosentase nilai batas rugi laba

Kapasitas pengembalian modal (rate of return)

Waktu minimal untuk pengembalian modal

\section{HASIL DAN PEMBAHASAN}

a. Kegunaan dan pemasaran

Kegunaan : sebagai sarana untuk pembuatan sepatu pria.

Pemasaran : kebutuhan dalam negeri.

b. Spesifikasi produk

Nama : acuan sepatu plastik pria.

Bahan : HDPE

Berat : rata-rata $1,81 \mathrm{~kg}$ per pasang. c. Diagram alir kualitatip

Bahan

Proses

Sisa proses

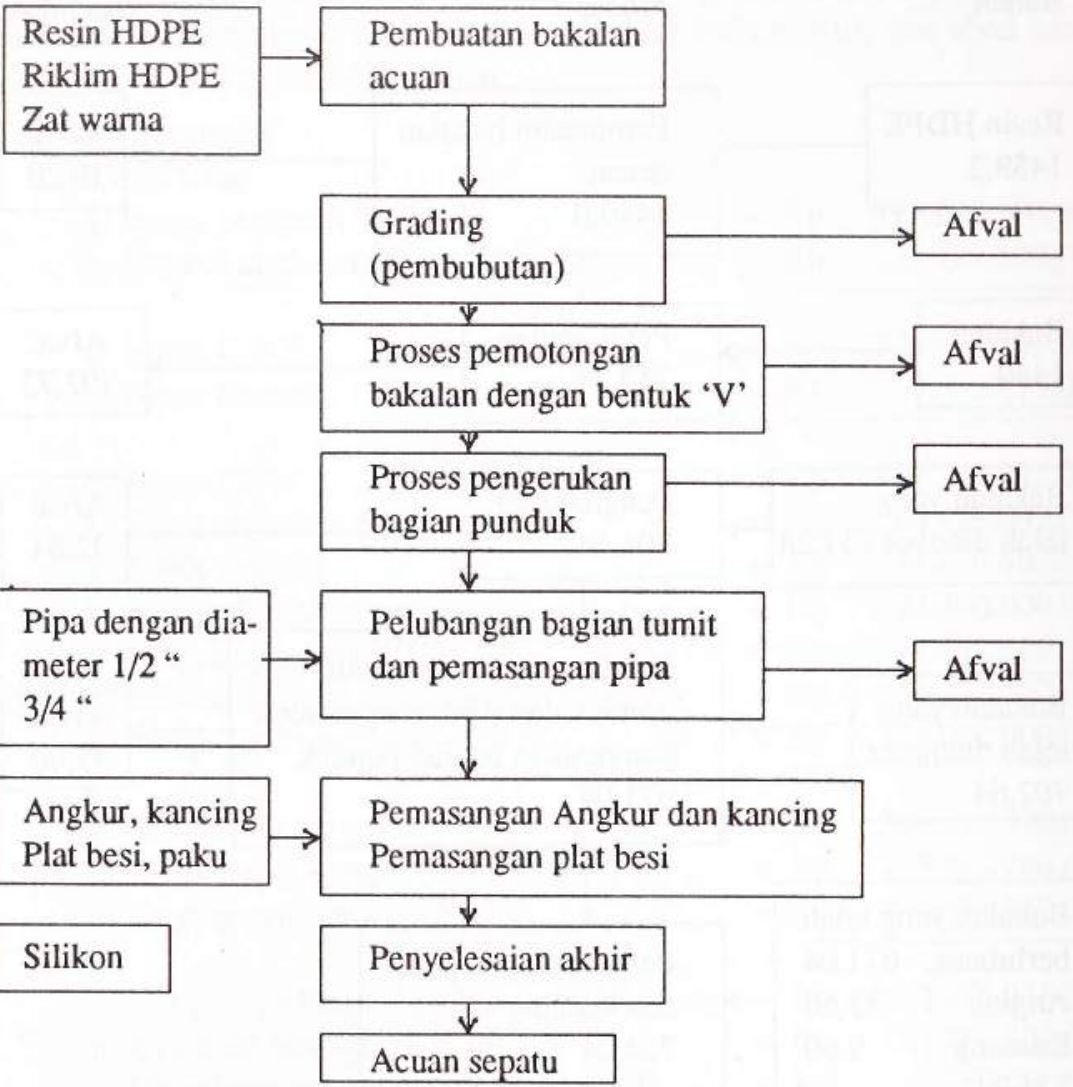


d. Diagram alir kuantitatip untuk 480 pasang acuan sepatu pria. (angka-angka dalam kilogram)

Bahan

Proses

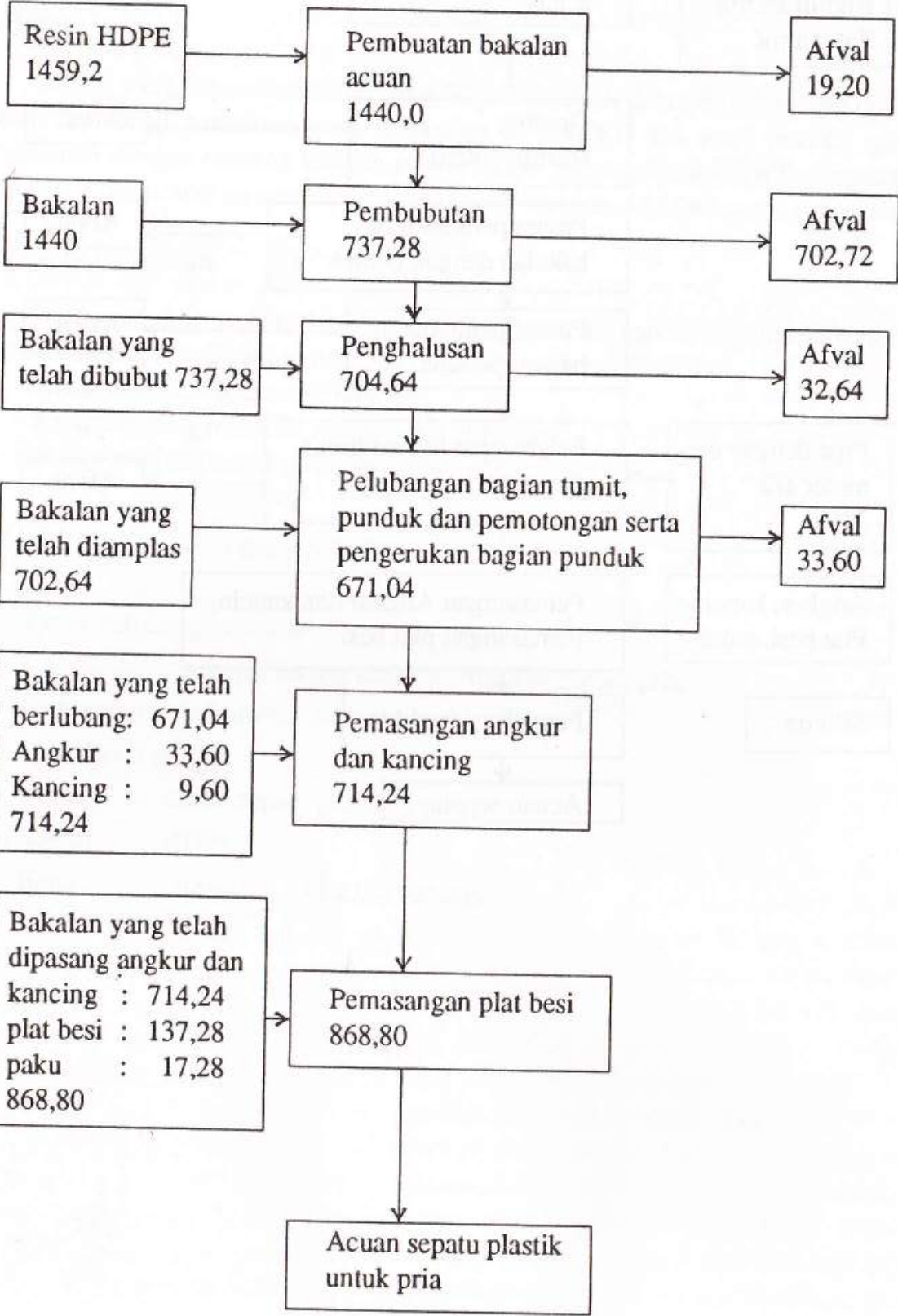

\section{PERHITUNGAN EKONOMI}

Hasil yang didapat dari perhitungan ini akan memberikan gambaran berapa besarnya modal yang dibutuhkan untuk pendirian pabrik acuan sepatu plastik HDPE. Dalam perhitungan ini 1 tahun $=288$ hari kerja efektif, dan afval yang dihasilkan dari sisa pembubutan dijual.

1. Perhitungan modal

\subsection{Modal tetap}
a. Harga peralatan, fob
$=\operatorname{Rp} \quad 721.225 .000,00$
b. Ongkos angk, kapal laut, $10 \%$ (a)
c. Harga C \& F
d. Biaya asuransi, $1 \%$ (c)
e. Harga CIF
f. Biaya angkutan darat, $10 \%$ (c)
g. MPO, $2 \%$ (a)
$=\mathrm{Rp} \quad 72.122 .500,00$
h. Harga alat dalam negri
i. Pemasangan alat, $10 \%(\mathrm{a}+\mathrm{h})$
j. Service fasilitas \& yard imp. $10 \%(a+h)$
k. Tanah dan bangunan
1. Total biaya langsung
m. Engineering + supervision $15 \%$ (1)
n. Ongkos pemborong $10 \%$ (1)
$=\operatorname{Rp} \quad 793.347 .500,00$
$=\mathrm{Rp} \quad 7.933 .475,00$
$=\operatorname{Rp} \quad 801.280 .975,00$
$=\mathrm{Rp} \quad 80.128 .097,00$
$=\mathrm{Rp} \quad 14.424 .500,00$
$\begin{array}{ll}=\mathrm{Rp} & 22.700 .000,00\end{array}$
$\begin{array}{ll}\mathrm{Rp} & 74.392 .500,00\end{array}$
$=\mathrm{Rp} \quad 74.392 .500,00$
$=\mathrm{Rp} \quad 230.000 .000,00$
$=\operatorname{Rp} 1.306 .318 .572,00$
$=\operatorname{Rp} \quad 195.947 .786,00$
$=\mathrm{Rp} \quad 130.631 .857,00$
o. Total biaya langsung + biaya tak langsung $=\mathrm{Rp} 1.632 .898 .215,00$ p. Biaya tak terduga $10 \%$ (o)
$=\operatorname{Rp} \quad 163.289 .822,00$
q. Persediaan mata gergaji $1.383 \times 1000=$ Rp $\quad 1.383 .000,00$
r. Persediaan mata bor $277 \times 1000 \quad=R p \quad 277.000,00$
Jumlah modal tetap
$=\operatorname{Rp} 1.797 .848 .037,00$

1.2. Modal kerja
a. Bahan baku 3 bulan
$=\operatorname{Rp} \quad 424.696 .320,00$
b. Listrik 3 bulan
c. Gaji 3 bulan
$=\mathrm{Rp} \quad 4.346 .246,00$
$=\operatorname{Rp} \quad 23.550 .000,00$
d. Pengemasan 3 bulan
$=R p \quad 7.200 .000,00$
$=\operatorname{Rp} \quad 459.792 .566,00$

Total modal $=$ modal tetap + modal kerja 3 bulan

$=\operatorname{Rp~1.797.848.037,00+Rp~459.792.566,00~}$

$=\operatorname{Rp} 2.257 .640 .603,00$ 
2. Perhitungan total biaya produksi

2.1. Biaya tidak tetap 1 tahun
a. Bahan baku 1 tahun
b. Pengemasan 1 tahun
c. Listrik 1 tahun

$=\operatorname{Rp} 1.359 .028 .224,00$

$\begin{array}{ll}=\mathrm{Rp} & 23.040 .000,00\end{array}$

$\begin{array}{ll}=\mathrm{Rp} & 13.916 .820,00\end{array}$

2.2. Biaya tetap 1 tahun
a. Gaji 1 tahun
b. Pemeliharaan, $2 \%$ x modal tetap
c. Bunga modal
$15 \% \times$ modal tetap
$18 \% \times$ modal kerja
d. Penyusutan, $8 \%$ x modal tetap
e. Biaya umum, $10 \%$ x gaji

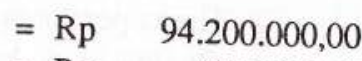
$=\mathrm{Rp} \quad 956.960,70$
$\begin{array}{ll}=\mathrm{Rp} & 269.677 .205,50\end{array}$

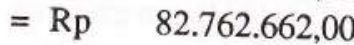
$=\mathrm{Rp} \quad 143.827 .842,90$
$\begin{array}{ll}\text { Rp } & 9.420 .000,00\end{array}$
$=\operatorname{Rp} \quad 635.844 .671,10$

$=\operatorname{Rp} 1.395 .985 .044,00$

\section{b. Total biaya produksi}

c. Keuntungan sebelum pajak

d. Pajak Perusahan $20 \%$

e. Keuntungan sesudah pajak
$=\operatorname{Rp} 2.031 .829 .715,00$

$=\operatorname{Rp} \quad 627.631 .405,00$

$=\mathrm{Rp} \quad 125.526 .281,00$

$=\operatorname{Rp} \quad 502.105 .124,00$

5. Perhitungan pengembalian modal

5.1. Prosen keuntungan untuk mengembalikan modal

Total biaya produksi = biaya tidak tetap + biaya tetap

$=\operatorname{Rp} 1.395 .985 .044,00+R p 635.844 .671,00$

$=\operatorname{Rp} 2.031 .829 .715,00$

3. Perhitungan harga pokok

Harga pokok $=\frac{\text { total biaya produksi }}{\text { jumlah produksi per tahun }}$

Rp 2.031.829.715,00

138.240

$=\quad \operatorname{Rp} 14.697,85 /$ pasang

4. Perhitungan keuntungan

a. Hasil penjualan per tahun 138.24 x Rp $18.500,00$

Sisa afval per pasang $1,64 \mathrm{~kg}$

$=1,64 \times 0,9 \times 480 \times 288 \times R p 500,00$

$=\operatorname{Rp} 2.557 .440 .000,00$

$=\operatorname{Rp} \quad 102.021 .120,00$

$=\operatorname{Rp} 2.659 .461 .120,00$
Keuntungan sebelum pajak

a. Sebelum pajak = total modal

x $100 \%$

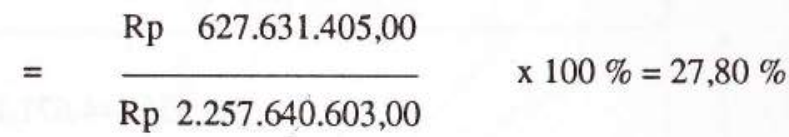

b. Sesudah pajak $=\frac{\text { Keuntungan sesudah pajak }}{\text { total modal }} \times 100 \%$

$=\frac{\operatorname{Rp~} 502.105 .124,00}{\operatorname{Rp} 2.257 \cdot 640.603,00} \quad \times 100 \%=22,24 \%$

5.2. Waktu pengembalian modal a. Sebelum pajak $=\frac{\text { total modal }}{\text { Keuntungan sebelum pajak }+ \text { penyusutan }}$ $x 1$ th

Rp 2.257.640.603,00

Rp 627.631.405,00 + Rp 143.827.842,90

$=2$ th 11 bulan

b. Sesudah pajak

total modal

$\overline{\text { Keuntungan sesudah pajak }+ \text { penyusutan }}$ 


\section{$=$ Rp 502.105.124,00 + Rp 143.827.842,90 \\ $=3$ th 6 bulan}

6. Perhitungan Batas Rugi Laba
6.1. Nilai Batas Rugi Laba
Biaya tetap$$
\text { 1. } \frac{\text { Biaya tidak tetap }}{\text { penjualan }}
$$
$=1.395 .985 .044,00$
1 - $\overline{2.577 .440 .000,00}$
Rp 635.844.671,10
$=\quad \operatorname{Rp} 1.387 .146 .821,00$
6.2. Prosentase Batas Rugi Laba $=\frac{\mathrm{Rp} 1.387 .146 .821,00}{\mathrm{Rp} 2.577 .440 .000,00} \times 100 \%$
$=53,82 \%$

$\begin{array}{rlr}\text { 6.3. Kapasitas Batas Rugi Laba } & = & 53,82 \times 138.240 \text { pasang } \\ & = & 7.440 .077 \text { pasang }\end{array}$
Kurva Batas Rugi Laba

$\begin{array}{lllr}\text { Biaya tidak tetap } & =\mathrm{Rp} & 1.395 .987 .044,00 \\ \text { Biaya tetap } & =\mathrm{Rp} & 635.844 .671,00 \\ \text { Total biaya produksi } & =\mathrm{Rp} & 2.031 .829 .715,00 \\ \text { Total penjualan } & =\mathrm{Rp} & 2.557 .440 .000,00 \\ \text { Persetase batas rugi laba } & =53,82 \% & \end{array}$

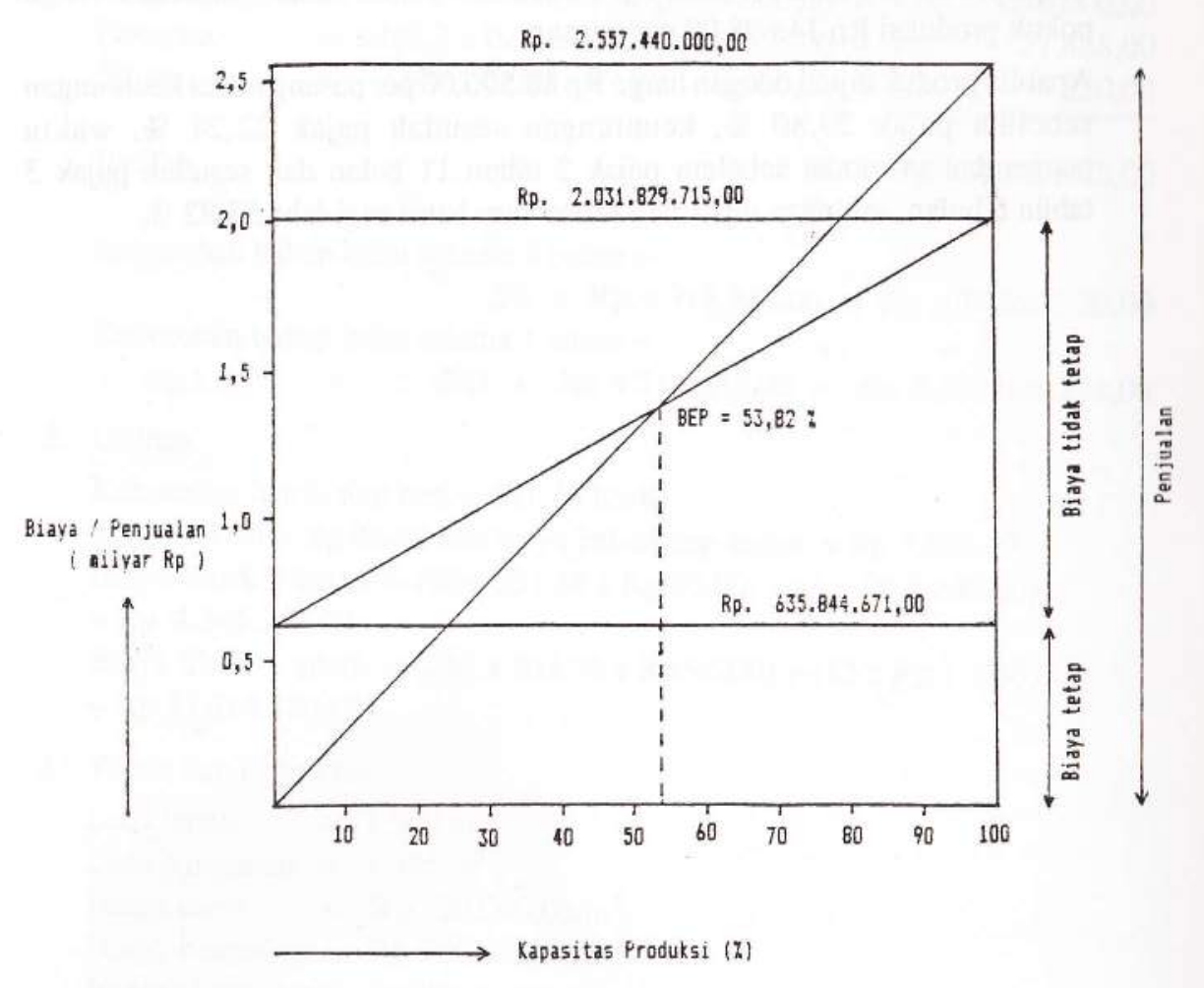




\section{KESIMPULAN}

Berdasarkan perhitungan analisa ekonomi dapat disimpulkan sebagai berikut :

- Dengan kapasitas produksi 480 pasang per hari atau 138.240 pa-sang per tahun maka modal yang dibutuhkan sebesar Rp 2.257.640.603,00 yang terdiri dari modal tetap Rp 1.797.848.037,00 dan modal kerja Rp 459.729.566,00

- Tenaga kerja yang dapat diserap 61 orang.

- Biaya produksi 1 tahun sebesar Rp 2.031.829.715,00, maka diperoleh harga pokok produksi Rp 14.698,00 per pasang.

- Apabila produk dijual dengan harga Rp 18.500,00 per pasang maka keuntungan sebelum pajak $27,80 \%$, keuntungan sesudah pajak $22,24 \%$, waktu pengembalian modal sebelum pajak 2 tahun 11 bulan dan sesudah pajak 3 tahun 6 bulan, sehingga diperoleh prosentase batas rugi laba 53,82\%.

\section{LAMPIRAN}

1. Bahan Baku

Kebutuhan bahan baku 1 hari:

$\begin{array}{llrllr}\text { Resin HDPE } & = & 729,6 \times & \mathrm{Rp} & 2.500,00=\mathrm{Rp} & 1.824 .000,00 \\ \text { Riklim HDPE } & = & 729,6 \times \mathrm{Rp} & 1.500,00=\mathrm{Rp} & 1.094 .400,00 \\ \text { Paku } & = & 17,2 \times \mathrm{Rp} & 800,00=\mathrm{Rp} & 13.760,00 \\ \text { Plat besi } & = & 16 \times & \mathrm{Rp} & 20.000,00=\mathrm{Rp} & 320.000,00 \\ \text { Angkur/engsel } & = & 480 \times \mathrm{Rp} & 3.000,00=\mathrm{Rp} & 1.440 .000,00 \\ \text { Pewarna } & =1459,2 \times 0,001 \times \mathrm{Rp} & 15.000,00=\mathrm{Rp} & 21.888,00 \\ \text { Silikon } & = & 480 \times 0,001 \times \mathrm{Rp} & 10.000,00=\mathrm{Rp} & 4.800,00 \\ & & & & \end{array}$

Jumlah

Rp $\quad 4.718 .848,00$

Kebutuhan bahan baku selama 3 bulan $=$

$90 \times \operatorname{Rp} 4.718 .848,00=\operatorname{Rp} 424.696 .320,00$

Kebutuhan bahan baku selama 1 tahun $=$

$288 \times$ Rp $4.718 .848,00=\operatorname{Rp~1.359.028.224,00~}$

2. Utilitas

Kebutuhan listrik tiap hari $=501,76 \mathrm{Kwh}$

Tarip $1 \mathrm{Kwh}=\mathrm{Rp} 96,00$ dan biaya beban tiap bulan $=\mathrm{Rp} 3.680,00$

Biaya listrik 3 bulan $=(90 \times 501,76 \times R p 96,00)+(3 \times R p 3.680,00)$

$=\operatorname{Rp} 4.346 .246,00$

Biaya listrik 1 tahun $=(288 \times 501,76 \times \operatorname{Rp} 96,00)+(12 \times R p 3.680,00)$

$=\mathrm{Rp} 13.916 .820,00$

3. Tanah dan bangunan
Luas tanah
$=1.500 \mathrm{~m}^{2}$
Luas bangunan $=1.045 \mathrm{~m}^{2}$
Harga tanah $=\operatorname{Rp} 20.000,00 / \mathrm{m}^{2}$
Harga bangunan $=$ Rp 200.000,00/ $\mathrm{m}^{2}$
Jumlah harga tanah dan bangunan $=$
$=(1.500 \times \operatorname{Rp} 20.000,00)+(1.045 \times \operatorname{Rp} 200.000,00)$
$=\operatorname{Rp} 239.000 .000,00$

4. Pengemasan

Dalam 1 hari memproduksi 480 pasang, tiap 12 pasang dikemas dalam kotak kayu, tiap 1 kotak kayu harganya Rp 2.000,00.

$90 \times 480 \times \operatorname{Rp} 2.000,00$

Kebutuhan pengemas selama 3 bulan $=$

$=\quad$ Rp. $7 \cdot 200 \cdot 000,00$ 
5. Peralatan

Jumlah harga peralatan $=\operatorname{Rp} 768.955 .000,00$

6. Jumlah dan gaji karyawan

\begin{tabular}{|c|c|c|c|}
\hline No Jenis pekerjaan & $\begin{array}{l}\text { Jumlah } \\
\text { karyawan }\end{array}$ & $\begin{array}{r}\text { Gaji/bulan/ } \\
\text { orang, Rp }\end{array}$ & $\begin{array}{r}\text { Jumlah gaji/ } \\
\text { bulan, Rp }\end{array}$ \\
\hline \multicolumn{4}{|l|}{ I. Pekerja pabrik } \\
\hline 1. Mencetak bakalan acuan & 6 & $90.000,00$ & $540.000,00$ \\
\hline 2. Membubut bakalan acuan & 2 & $130.000,00$ & $260.000,00$ \\
\hline \multicolumn{3}{|l|}{ 3. Membuat lubang pada bagian } & $200.000,00$ \\
\hline \multicolumn{4}{|l|}{$\begin{array}{l}\text { 4. Memotong bakalan acuan dengan } \\
\text { bentuk ' } V \text { ', mengeruk dan }\end{array}$} \\
\hline $\begin{array}{l}\text { memasang angkur dan kancing } \\
\text { 5. Memotong plat besi dan meng- }\end{array}$ & \multicolumn{2}{|c|}{$\begin{array}{l}\text { 5. Memotong plat besi dan meng- } \\
\text { gerinda }\end{array}$} & $200.000,00$ \\
\hline $\begin{array}{l}\text { gerinda } \\
\text { 6. Memasang plat besi pada bagian }\end{array}$ & \multicolumn{2}{|c|}{ 6. Memasang plat besi pada bagian } & $600.000,00$ \\
\hline bawah acuan & 4 & $100.000,00$ & $400.000,00$ \\
\hline 7. Penyelesaian acuan & 4 & $100.000,00$ & $400.000,00$ \\
\hline \multicolumn{4}{|l|}{ 8. Memproses afval bakalan } \\
\hline \multicolumn{4}{|l|}{ 9. Memproses serpihan afval } \\
\hline 10. Tenaga generator & 3 & $100.000,00$ & $300.000,00$ \\
\hline 11. Pengawas & 5 & $200.000,00$ & $1.000 .000,00$ \\
\hline 12. Perbaikan mesin (maintenance) & 3 & $100.000,00$ & $300.000,00$ \\
\hline 13. Gudang & 3 & $60.000,00$ & $180.000,00$ \\
\hline \multirow[t]{2}{*}{ 14. Keamanan } & 6 & $50.000,00$ & $300.000,00$ \\
\hline & 51 & & $5.080 .000,00$ \\
\hline \multicolumn{4}{|l|}{ II Pekerja kantor } \\
\hline 1. Manager & 1 & $900.000,00$ & $900.000,00$ \\
\hline 2. Manager produksi & 1 & $600.000,00$ & $600.000,00$ \\
\hline 3. Ka. Bag. Administrasi & 1 & $500.000,00$ & $500.000,00$ \\
\hline \multirow[t]{2}{*}{ 4. Staf administrasi } & 7 & $110.000,00$ & $770.000,00$ \\
\hline & 10 & & $2.770 .000,00$ \\
\hline
\end{tabular}

Jumlah I dan II

\section{2}

$=\quad \operatorname{Rp} 23.040 .000,00$

\section{DAFTAR PUSTAKA}

1. Perry's, Chemical Engineer's Handbook, third edition.

2. Peter and Thimmerhaus, Plant Design and Economics for Chemical Engineer, Mc Craw Hill, Kogakusha, 1978.

3. Suad Husnan \& Suwarsono, Studi Kelayakan Proyek Konsep Teknik dan Penyusunan Laporan, BPFE UGM, Yogyakarta, 1984.

4. Soelkam dkk, Laporan Penelitian Pembuatan Satu Seri Acuan Plastik, Swakelola pengembangan Acuan BBKKP, 1987. 